\title{
Levels of ochratoxins in Mediterranean red wines
}

Rebeca Remiro ${ }^{\mathrm{a}}$, Angel Irigoyen ${ }^{\mathrm{a}}$, Elena González-Peñas ${ }^{\mathrm{a} *}$, Elena Lizarraga ${ }^{\mathrm{a}}$, Adela López de Cerain ${ }^{\mathrm{b}}$

${ }^{a}$ Department of Organic and Pharmaceutical Chemistry

${ }^{\mathrm{b}}$ Department of Pharmacology and Toxicology

C.I.F.A. Faculty of Pharmacy,., University of Navarra

Irunlarrea 1, 31008, Pamplona, Navarra, Spain

*Corresponding author: Elena González-Peñas PhD: Tel: +34 948 425653. Fax: +34 948 425652. E-mail: mgpenas@unav.es

E-mail addresses of all coauthors: Rebeca Remiro PhD: rremiro@alumni.unav.es. Angel Irigoyen: angelirigoyen@unav.es. Elena Lizarraga PhD: elizarraga@unav.es. Adela López de Cerain PhD: acerain@unav.es. 


\section{ABSTRACT}

The co-occurrence of ochratoxin A (OTA) and its five analogs (OTB, OTC, MeOTA, MeOTB and EtOTB) in 96 red wine samples from Mediterranean countries has been demonstrated, for the first time, in this study.

OTA was detected in $99 \%$ of the samples ( $<$ LOD - $\left.455 \mathrm{ng} \cdot \mathrm{L}^{-1}\right)$. This mycotoxin appeared simultaneously with OTB $\left(2.05-119 \mathrm{ng} \cdot \mathrm{L}^{-1}\right)$ in all the samples and in $89.6 \%$ of them OTC $\left(<\mathrm{LOD}-31.5 \mathrm{ng} \cdot \mathrm{L}^{-1}\right)$ also accompanied both. OTB appears at comparable levels and incidence just like OTA does, and OTC median concentration is approximately $10 \%$ of that of OTA. A high statistical association was found between the concentrations of OTA-OTB and OTA-OTC. MeOTA, MeOTB and EtOTB were detected in $62.5,83.3$ and $83.3 \%$ of the samples, respectively. In $44.8 \%$ of the wines, the 6 ochratoxins appeared simultaneously.

There was no evidence for ochratoxin A levels being greater in wines from Southern Europe than those described from North Europe. Samples from North Africa presented statistically the highest values for OTA, OTB, OTC and EtOTB.

Keywords: Ochratoxin A, ochratoxin B, ochratoxin C, ochratoxin analogs, wine, cooccurrence. 


\section{Introduction}

Ochratoxins are toxic compounds produced in the secondary metabolism of several filamentous fungi of Aspergillus and Penicillium genera. Ochratoxin A (OTA) has been the most studied one, in view of its toxicity and incidence. Its natural presence has been described worldwide in agricultural commodities such as grapes, cereals, spices and dried fruits. The International Agency for Research on Cancer (IARC) classified this mycotoxin as a possible carcinogen for humans (Group 2B).

Other related compounds may also accompany OTA in foods as they are produced by the same fungal species. For instance, co-occurrence of ochratoxin B (OTB) and OTA was reported in spices (Scheuer \& Gareis, 2002), traditional Chinese medicines (Han, Zheng, Luan, Ren \& Wu, 2010) and some commercial foods in Japan (Tabata et al., 2008). And the simultaneous presence of OTA and its ethyl ester, ochratoxin $\mathrm{C}$ (OTC), in wines was described for the first time by Zimmerli \& Dick (1996).

The simultaneous presence of other ochratoxins along with OTA could change or even enhance the toxic potential of this mycotoxin (Pfohl-Leszkowicz \& Manderville, 2007) but the knowledge of their co-occurrence in food or their combined toxicological effects is still limited.

Wine is the second largest source of OTA intake for humans in Europe (JECFA, 2007; SCOOP, 2002) and a Provisional Tolerable Weekly Intake (PTWI) of $100 \mathrm{ng} \cdot \mathrm{kg}$ $\mathrm{bw}^{-1} \cdot$ week $^{-1}$ was established (JECFA, 2007). In order to minimize public health risk, the European Commission established a maximum level of $2 \mu \mathrm{g} \cdot \mathrm{L}^{-1}$ for OTA in wine $(\mathrm{EC}$, 2006). 
The presence of this mycotoxin in red wine has been reported in several countries including the Mediterranean ones (see table 1). However, due to the wide variety of monitored wines and the differences in analytical methodology, especially as regards the different limits of detection (LOD) achieved, it is difficult to make comparisons among countries related to the percentage of positive samples or the levels of contamination (SCOOP, 2002).

Several factors, such as climate, grape cultivation, and winemaking techniques, influence the levels of OTA in wines. Some authors have stated that South Europe red wines are more contaminated with this mycotoxin than those produced in northern regions, due to the warmest climatic conditions (Brera et al., 2008, Otteneder \& Majerus, 2000). However, the SCOOP report and the European Food Safety Authority pointed out that the mean OTA concentrations seem to be quite close together and that no systematic differences between countries could be found (EFSA, 2006).

Due to the fact that ochratoxigenic fungi can produce OTA and its related compounds, it is more realistic to consider that under natural conditions, wine could be contaminated with a mixture of fungal metabolites. OTC is more toxic than OTA in cell cultures (Müller et al., 2003) and it is rapidly converted into OTA in the body (PfohlLeszkowicz et al., 2007). OTB has demonstrated its cytotoxicity (Dietrich, O'Brien, Stack \& Heussner, 2001), nephrotoxicity (Mally et al., 2005) and teratogenicity (O'Brien, Prietz \& Dietrich, 2005). However, surveys for the simultaneous presence of several ochratoxins in wine are lacking and this should be investigated in order to avoid underestimating the total intake of ochratoxins and their possible adverse effects. 
In a previous research work of our group, ochratoxin A and five analogs: ochratoxin B, methylochratoxin A (MeOTA), methylochratoxin B (MeOTB), ethylochratoxin A and ethylochratoxin B (EtOTB) (Figure 1) were determined in red wine samples from Navarra (Spain) (Remiro, González-Peñas, Lizarraga \& López de Cerain, 2012). Due to the low LOD achieved for the mycotoxins, detectable levels of OTA and OTB were found in $100 \%$ of the samples, and $71 \%$ showed also the presence of OTC. The six ochratoxins appeared simultaneously in $18 \%$ of the samples. That study concluded that ochratoxin intake from wine can be underestimated when only is assessed by OTA analysis.

In this study, a previously validated HPLC-FLD method was applied for the determination of the simultaneous presence of ochratoxin A and its five analogs in 96 red wine samples from Mediterranean countries. The aims of this work were: to investigate the contamination and the simultaneous presence of six ochratoxins in red wines from different countries of the Mediterranean region, examining the possible influence of their origins upon the concentrations and the correlation between the presence of ochratoxins. Also, the obtained OTA levels were compared with other previously described in the bibliography.

\section{Material and methods}

\subsection{Samples}

A total of 96 red wine samples from Spain, France, Italy, Croatia, Greece, Turkey, Israel, and North-Africa (Tunisia and Algeria) were analyzed. They were purchased from different supermarkets in Spain and Greece, and on-line from some web sites. From each country, twelve bottles of red wine were chosen. The origin of the wines, their alcoholic percentage and the interval of vintage years are indicated in table 2.

\subsection{Chemicals}


Ochratoxin A (Ref: O1877) and B (Ref: O1382), acetonitrile and methanol CHROMASOLV $^{\circledR}$ for HPLC were purchased from Sigma-Aldrich (St. Louis MO, USA) and formic acid from Panreac (Barcelona, Spain). Instamed Phosphate Buffered Saline (Dulbecco) w/o $\mathrm{Ca}^{2+}, \mathrm{Mg}^{2+}$ was purchased from Biochrom AG (Berlin, Germany). Ochraprep ${ }^{\circledR}$ immunoaffinity columns (IAC) were obtained from R-Biopharm Rhône Ltd (Glasgow, UK). Millipore type I water was used to prepare all of the aqueous solutions and it was obtained daily from a Milli-Q water purifying system. Non-sterile Millex ${ }^{\circledR}$-HV syringe filters $0.45 \mu \mathrm{m}$, PVDF, $13 \mathrm{~mm}$, were purchased from Millipore Iberica S.A.U. (Madrid, Spain). Preassembled vial kit (amber screw top writeon, caps and septa) and deactivated glass inserts were acquired from Agilent Technologies (Madrid, Spain). Methyl and ethyl esters of OTA and OTB were synthesized from the corresponding compound after alcoholic esterification in acidic media. Purity of these compounds (absence of OTA contamination) was confirmed by HPLC-FLD (Remiro, Ibáñez-Vea, Gónzalez-Peñas \& Lizarraga, 2010).

\subsection{Analytical method}

Ochratoxins were quantified according to the method of Remiro et al. (2010). Briefly, ochratoxins were extracted with immunoaffinity columns from $50 \mathrm{~mL}$ of red wine adjusted to $\mathrm{pH} 7.2$ and they were eluted with methanol. This solvent was evaporated and the residue was redissolved in $250 \mu \mathrm{L}$ of mobile phase, consisting of $42 \%$ acetonitrile and $58 \%$ of an aqueous solution of formic acid $(0.4 \%)$. The injection volume was $100 \mu \mathrm{L}$.

Analysis of ochratoxins was carried out on an HPLC 1100 (Agilent Technologies) equipped with a C18 column (Zorbax Eclipse XDB-C18, 15 x $0.46 \mathrm{~cm} ; 5 \mu \mathrm{m}$ ) and a fluorescence detector. The mobile phase consisted of a gradient of acetonitrile and formic acid $(0.4 \%)$ at a flow rate of $1.0 \mathrm{~mL} \cdot \mathrm{min}^{-1}$. 
Recovery values for OTB, OTA, MeOTA and OTC (81.7, 93.5, 76.0, and $73.4 \%$ ), limits of detection $\left(0.16,0.32,0.21\right.$ and $\left.0.17 \mathrm{ng} \cdot \mathrm{L}^{-1}\right)$, and quantification (LOQ) $\left(0.50 \mathrm{ng} \cdot \mathrm{L}^{-1}\right)$ values obtained during the validation process were used in this study.

MeOTB and EtOTB were approximately quantified assuming analytical behavior similar to their respective analogs MeOTA and EtOTA andusing the calibration curves, recoveries, and limits of detection and quantification of their OTA analogs. This was assumed due to the fact that their absorptivity coefficients were unknown and their exact concentrations could not be determined (Remiro et al., 2012).

For confirmatory purposes, the $10 \%$ of the red wine samples were reanalyzed in an Agilent Technologies 1200 liquid chromatographic system coupled to a MSD Trap XCT Plus mass spectrometer (G2447A model) and equipped with an electrospray ionization source (ESI), in the analytical conditions described in Remiro et al. (2010). Ions monitored were as follows: OTB: $370,1[\mathrm{M}+\mathrm{H}]^{+}, 324.1,352.1,307.1$; OTA: 404.0 $[\mathrm{M}+\mathrm{H}]^{+}, 358.1,386.1,341.1$; MeOTB: $384.0[\mathrm{M}+\mathrm{H}]^{+}, 324.1,352.1,307.1$; EtOTB: $398.0[\mathrm{M}+\mathrm{H}]^{+}, 324.1,352.1,307.1$; MeOTA: $418.1[\mathrm{M}+\mathrm{H}]^{+}, 358.1,386.1,341.1$; OTC: $432.1[\mathrm{M}+\mathrm{H}]^{+}, 358.1,386.1,341.1$.

\subsection{Statistical methods}

Positive samples were considered those which concentrations were above the limit of detection. Median values were calculated taking into account all the levels encountered, including those between LOD and LOQ. Values under LOD were assumed to be a half of LOD. Mean values were calculated for the > LOQ levels. All analytical results were corrected with the recovery value and the concentration factor.

Ochratoxins levels obtained in different countries were analyzed with the KruskalWallis non-parametric test for non-dependent samples. Significant results $(p<0.05)$ 
were examined with the Bonferroni multiple comparison test. The non-parametric Spearman correlation coefficient was used to associate ochratoxin concentrations between each other. The statistical program UNStat1.0 was utilized (García-Granero, 2010).

\section{Results and discussion}

\subsection{Concentration of ochratoxins in Mediterranean red wines}

Whereas the presence of OTA in red wine has been extensively studied, the likely presence of other analogs in this matrix has not been examined, although some authors also detected OTC in wine (Zimmerli \& Dick, 1996). So, in this study, the cooccurrence of OTA and five analogs was evaluated in 96 red wine samples. OTB, OTA, MeOTA, OTC, MeOTB and EtOTB levels (\% of positives, minimum, maximum, mean and median values) in each country are shown in table 3. Summary of ochratoxins concentrations $\left(\mathrm{ng} \cdot \mathrm{L}^{-1}\right)$ found in wines of Mediterranean countries is shown in table 4 .

\subsubsection{Ochratoxin A}

OTA was detected in $99 \%$ of the analyzed samples. Only one French red wine contained this mycotoxin below the LOD.

No wine presented an OTA level higher than the maximum limit established by EU for wine $\left(2 \mu \mathrm{g} \cdot \mathrm{L}^{-1}\right)$. The highest value found in a sample was $455 \mathrm{ng} \cdot \mathrm{L}^{-1}$, four times lower than the EU limit, and it was from North Africa. The OTA mean and median concentrations of the 96 samples measured in this study were 54.2 and $19.1 \mathrm{ng} \cdot \mathrm{L}^{-1}$, respectively.

Taking into account the levels encountered in the different countries, the OTA median concentration followed the order: France $<$ Croatia $<$ Israel $<$ Italy $\approx$ Turkey $<$ 
Spain $<$ Greece $<$ North Africa. Only samples from North Africa showed statistically significant higher levels with regard to the other countries.

The low limits of detection and quantification of this analytical method gave a great percentage of positive samples. So a comparison among other works related to this must be cautious, likewise with regard to the levels of contamination or the differences among countries, due to the different ways of calculating mean and median values. Since some authors describe the mean of all values including those below the LOD as zero, $\mathrm{LOD}$ or $\mathrm{LOD} / 2$, and others calculate it taking into account only the levels above the LOQ or LOD (see Table 1). The median value is a better indication of tendency than the arithmetic mean when no normal distribution is considered, but it is a data scarcely given.

In Spain, a concentration range of $1.05-104 \mathrm{ng} \cdot \mathrm{L}^{-1}$ and a mean (median) value of $37.2(25.1) \mathrm{ng} \cdot \mathrm{L}^{-1}$ were obtained. This mean is similar to that described by Burdaspal \& Legarda (1999) and Quintela, Villarán, López de Armentia \& Elejalde (2011) in Spanish red wines (38 and $37 \mathrm{ng} \cdot \mathrm{L}^{-1}$, respectively). The median value seems to be similar than other works, although these described higher maximum levels (López de Cerain, González-Peñas, Jiménez, \& Bello, 2002, Bellí, Marín, Duaigües, Ramos \& Sanchis, 2004, Blesa, Soriano, Moltó, \& Mañes, 2004).

In French wines, the range of positive samples was 0.20 to $88.3 \mathrm{ng} \cdot \mathrm{L}^{-1}$, with a mean value of $33.6 \mathrm{ng} \mathrm{L}^{-1}$. Other authors found similar mean values in French wines: 28 $\mathrm{ng} \cdot \mathrm{L}^{-1}$ (Rosa, Fraga, Santana, Magnoli \& Dalcero, 2004), $58 \mathrm{ng} \cdot \mathrm{L}^{-1}$ (Quintela, Villarán, López de Armentia \& Elejalde, 2012), $70 \mathrm{ng} \cdot \mathrm{L}^{-1}$ (Otteneder \& Majerus, 2000); or higher: $225 \mathrm{ng} \cdot \mathrm{L}^{-1}$ (Burdaspal \& Legarda, 1999).

Italy is the country in which the OTA presence in wines has been the most studied, and also, one of the countries where highest OTA levels have been described, 
near $8 \mu \mathrm{g} \cdot \mathrm{L}^{-1}$ (Brera et al., 2008, Visconti, Pascale \& Centonze, 1999). In the present work, levels were between 5.18 and $286 \mathrm{ng} \cdot \mathrm{L}^{-1}$ (mean $53.9 \mathrm{ng} \cdot \mathrm{L}^{-1}$ ), similar than those described by Burdaspal \& Legarda (1999). The means reported by other authors ranged between 0.12 and $1.24 \mu \mathrm{g} \cdot \mathrm{L}^{-1}$ (Visconti et al., 1999, Pietri, Bertuzzi, Pallaroni \& Piva, 2001, Bacaloni, Cavaliere, Faberi, Pastorini, Samperi \& Lagana, 2005, Perrone, Nicoletti, Pascale, De Rossi, De Girolamo \& Visconti, 2007, Brera et al., 2008, Spadaro, Lore, Garibaldi \& Gullino, 2010).

The OTA levels found in Croatia red wines ranged between 0.36 and $61.3 \mathrm{ng} \cdot \mathrm{L}^{-}$ ${ }^{1}$, with a mean (median) concentration of $18.8(7.65) \mathrm{ng} \cdot \mathrm{L}^{-1}$. These values were similar than the described by Domijan \& Peraica (2005) and Flajs, Domijan, Ivic, Cvjetkovic, \& Peraica (2009), although the maximum value found in this study is lightly higher than the reported by these authors (47 and $21 \mathrm{ng} \cdot \mathrm{L}^{-1}$ respectively).

The OTA mean and median concentrations of the Greek wines analyzed were 59.4 and $31.7 \mathrm{ng} \cdot \mathrm{L}^{-1}$, respectively (range: $4.35-212 \mathrm{ng} \cdot \mathrm{L}^{-1}$ ). These mean and maximum values were ten times lower than the previously described and the medians looked on the same order (Stefanaki, Foufa, Tsatsou-Dritsa \& Dais, 2003, Soufleros, Bouloumpasi \& Tricard 2003). Stefanaki et al. (2003) indicated also, greater OTA levels in the South than in the North of the country, being the greatest levels in the Egeo islands. In this study, there were not samples enough in order to confirm this hypothesis, but the greatest levels obtained were from two wines of this region.

The OTA levels reported by other authors in Turkish wines were greater than the obtained in this study (mean: $31.1 \mathrm{ng} \cdot \mathrm{L}^{-1}$, range: $2.91-101 \mathrm{ng} \cdot \mathrm{L}^{-1}$ ) (Altiokka, Can, Atkosar \& Aboul-Enein, 2009, Anli, Çabuk, Vural \& Başpinar, 2005, Var \& Kabak, 2007). Altiokka et al. (2003) obtained a mean value of $2.85 \mu \mathrm{g} \cdot \mathrm{L}^{-1}(\mathrm{n}=20)$ and a 
maximum OTA level of even $7.96 \mu \mathrm{g} \cdot \mathrm{L}^{-1}$, being the highest levels of contamination found in bibliography.

As regards Israeli or North-African wines, no studies about the presence of OTA were found in the scientific literature. Only Zimmerli \& Dick (1996) analyzed two samples of red wine from Algeria and one from Tunisia (194, 292 and $388 \mathrm{ng} \cdot \mathrm{L}^{-1}$, respectively) with similar results as the obtained in this study.

\subsubsection{Ochratoxin $B$}

All Mediterranean wines analyzed were contaminated with ochratoxin B. The mean and median obtained values were 23.5 and $13.4 \mathrm{ng} \cdot \mathrm{L}^{-1}$.

The highest value $\left(119 \mathrm{ng} \cdot \mathrm{L}^{-1}\right)$ corresponds to a sample from the Calabria Italian region, in the south of the country. The lowest concentration was found in a French wine. Croatian wines were the less contaminated with this mycotoxin, as they had the lowest mean and median values.

OTB median concentrations are in the following order: Croatia $<$ France $\approx$ Turkey $<$ Italy $<$ Spain $<$ Israel $<$ Greece $<$ North Africa. Samples from this last region showed again statistical highest OTB values.

\subsubsection{Ochratoxin $C$}

$89.6 \%$ of the 96 wines analyzed are contaminated with OTC. The mean and median obtained concentrations are 5.2 and $2.32 \mathrm{ng} \cdot \mathrm{L}^{-1}$, respectively. A sample from Tunisia has the highest value of $31.5 \mathrm{ng} \cdot \mathrm{L}^{-1}$. The concentrations obtained in wines from North Africa are statistically different and higher than that obtained in samples from other origins. OTC concentrations follow the increasing order: Croatia $<$ France $<$ Israel $<$ Turkey $\approx$ Catalonia $<$ Greece $<$ Italy $<$ North Africa.

\subsubsection{Methylochratoxin A}


Sixty of 96 red wines $(62.5 \%)$ presented MeOTA above the limit of detection. The incidence of this ochratoxin was the slightest of the six studied. The highest value (48.2 $\mathrm{ng} \cdot \mathrm{L}^{-1}$ ) corresponded to a sample from Italia. Croatian and Turkish wines were the least contaminated as their median concentrations were below the limit of detection. The wines from North Africa, France, Italy, Greece, Spain and Israel show very low concentrations of MeOTA. According to the Bonferroni test, Croatian wines are significantly different from those of Italy, Greece and Israel. And MeOTA concentration in Israel wines is statistically different from those obtained in Croatia, Turkey, North Africa, France and Greece.

\subsubsection{Methylochratoxin B}

In $83.3 \%$ of the wine samples, MeOTB was detected. The highest value $(8.11$ $\mathrm{ng} \cdot \mathrm{L}^{-1}$ ) was obtained in a sample from Israel.

Wines from North Africa, Croatia and France were the least contaminated and showed significant differences with respect to the most contaminated wines (Italy and Israel).

\subsubsection{Ethylochratoxin B}

EtOTB was detected in $83.3 \%$ of the wine samples with values lower than the limit of detection $\left(0.17 \mathrm{ng} \cdot \mathrm{L}^{-1}\right)$. The highest value of $4.20 \mathrm{ng} \cdot \mathrm{L}^{-1}$ corresponded to a sample from Italia.

Wines from France, Italy and Israel were the least contaminated. Wines from North Africa had significant differences with respect to the concentrations in other countries.

\subsection{Simultaneous presence of ochratoxins and correlation between concentrations}

The co-occurrence of several mycotoxins in the same sample was demonstrated due to the fact that in $100 \%$ of them it were observed the co-occurrence of, at least, 2 
mycotoxins and in $44.8 \%$ of the samples, the six ochratoxins were found simultaneously. Five, four and three mycotoxins appeared simultaneously in $37.5,9.4$ and $7.3 \%$ of the samples, respectively.

The fact that OTA and OTB occurred simultaneously in the 100 and $99 \%$ of the samples, respectively, and that their median concentrations were 19.1 and $13.4 \mathrm{ng} \cdot \mathrm{L}^{-1}$, respectively, (Table 3) confirmed the assumption that OTA and OTB can appear simultaneously in food and feed (EFSA, 2006) and that their levels and incidence are comparable.

OTC co-occurred with both OTA and OTB in $89.6 \%$ of the samples and its median concentration was $2.32 \mathrm{ng} \cdot \mathrm{L}^{-1}$, being approximately the $10 \%$ of OTA value, like it was stated by Zimmerli \& Dick in 1996.

These results suggested that a relation between these ochratoxins could exist. The Spearman correlation test between OTA and OTB concentrations revealed a very large positive association $\left(\mathrm{r}_{\mathrm{s}}=0.897, \mathrm{CI}_{95 \%}: 0.849 ; 0.930\right)$. Spearman correlation test between OTA and OTC levels evidenced a nearly perfect correlation $\left(\mathrm{r}_{\mathrm{s}}=0.934, \mathrm{CI}_{95 \%}: 0.903\right.$; 0.956) (figure 2). These results imply that high levels of ochratoxin A could also involve high levels of ochratoxin $\mathrm{B}$ and $\mathrm{C}$, and also, that the presence of ochratoxins is underestimated if it is based in OTA surveillance.

\subsection{Influence of origin of samples}

In general, the concentrations obtained from each ochratoxin in each country are comparable, so it can not be assured that levels depend on the geographical origin, except in the case of wines from Tunisia and Algeria which statistical significant differences were revealed for OTB, OTA, OTC and EtOTB concentrations. With respect to methyl esters of OTA and OTB, their levels were higher in wines from Israel.

\subsection{Comparison between northern and southern European countries}


Some studies have concluded that wines from the Southern European countries are more susceptible to contamination by ochratoxin A due to the warm and Mediterranean climate (Brera et al., 2008, Otteneder \& Majerus, 2000).

However, several studies reported high values of OTA contamination from Northern Europe wines, for instance, $4.4 \mu \mathrm{g} \cdot \mathrm{L}^{-1}$ in a wine sample from Russia (Rusanova, Beloglazova, Goryacheva, Lobeau, Van Peteghem \& De Saeger, 2009) or the values described at the SCOOP report (2002): $1.90 \mu \mathrm{g} \cdot \mathrm{L}^{-1}$ (Finland); 2,49 $\mu \mathrm{g} \cdot \mathrm{L}^{-1}$ (Sweeden) and $3.10 \mu \mathrm{g} \cdot \mathrm{L}^{-1}$ (The Netherlands). These data are much higher than those found in this study in Mediterranean countries.

On the other hand, in Hungary (range: 30 to $533 \mathrm{ng} \cdot \mathrm{L}^{-1}$, mean: $117 \mathrm{ng} \cdot \mathrm{L}^{-1}$ ) or Slovakia (range: $<11$ to $\left.463 \mathrm{ng} \cdot \mathrm{L}^{-1}\right)$ (Varga, Kiss, Mátrai, Mátrai \& Téren, 2005, Belajová \& Rauova, 2007) were found levels of OTA similar to these obtained in Mediterranean countries. Also, these concentrations were comparable with other described in other parts of the world, like South America or Canada (Rosa et al., 2004, Ng, Mankotia, Pantazopoulos, Neil, \& Scott, 2004).

This confirms the hypothesis of the SCOOP report and the European Food Safety Authority which pointed out that no systematic differences between countries could be established (EFSA, 2006). The SCOOP report also stated the difficulty of making comparisons among countries due to the variety of analytical methodology, and this is more manifested when different data expression are used. Notice that the median concentrations offered in table 1 generally are similar, regardless of the country of origin.

\section{Conclusions}


This study determines for the first time the presence and the co-occurrence of six ochratoxins in red wines from different Mediterranean countries. OTA was found in the $99 \%$ of the samples, although no wine exceeded the maximum OTA limit of $2 \mu \mathrm{g} \cdot \mathrm{L}^{-1}$ established by the EU for this matrix.

OTA co-occurred with OTB in all the samples and in $89.6 \%$, OTC appeared simultaneously with them. In fact, a very high statistical association was found for the simultaneous presence of OTA-OTB and OTA-OTC.

Also, other ochratoxins, like MeOTA, MeOTB and EtOTB were found in the 62.5, 83.3 and $83.3 \%$ of the samples, respectively. The six ochratoxins co-occurred in $44.8 \%$ of the samples.

There was not a relationship among levels of ochratoxins and geographic origin of wines, except for wines from North Africa which presented statistically highest values for OTA, OTB, OTC and EtOTB.

From the results obtained in this study there was no evidence that levels of ochratoxin A in wines from southern European countries are greater than those described in Northern Europe, which coincides with the reported results in SCOOP (2002).

\section{Acknowledgements}

The authors are grateful to Ms. Laura Stokes for reviewing the English version of this manuscript. We thank the Project of Research of University of Navarra (PIUNA Projects) and CAN Foundation (Caja Navarra; "Proyecto: Tú eliges, tú decides") for the financial support received. We are also very grateful to Heleni Pontiki $\mathrm{PhD}$ who kindly sent us some Greek red wines.

\section{References}


Altiokka, G., Can, N. O., Atkosar, Z., \& Aboul-Enein, H. Y. (2009). Determination of ochratoxin A in Turkish Wines. Journal of Food and Drug Analysis, 17 (6), 467-473.

Anli, E., Çabuk, B., Vural, N., \& Başpinar, E. (2005). Ochratoxin A in Turkish wines. Journal of Food Biochemistry, 29 (6), 611-623.

Bacaloni, A., Cavaliere, C., Faberi, A., Pastorini, E., Samperi, R., \& Laganà, A. (2005). Automated on-line solid-phase extraction-liquid chromatography-electrospray tandem mass spectrometry method for the determination of ochratoxin $\mathrm{A}$ in wine and beer. Journal of Agricultural and Food Chemistry, 53 (14), 5518-5525.

Belajová, E., \& Rauova, D. (2007). Determination of ochratoxin A and its occurrence in wines of Slovakian retail. Journal of Food and Nutrition Research, 46 (2), 68-74.

Bellí, N., Marín, S., Duaigües, A., Ramos, A. J., \& Sanchis, V. (2004). Ochratoxin A in wines, musts and grape juices from Spain. Journal of the Science of Food and Agriculture, 84, 591-594.

Blesa, J., Soriano, J. M., Moltó, J. C., \& Mañes, J. (2004). Concentration of ochratoxin A in wines from supermarkets and stores of Valencian Community (Spain). Journal of Chromatography.A, 1054 (1-2), 397-401.

Brera, C., Debegnach, F., Minardi, V., Prantera, E., Pannunzi, E., Faleo, S., De Santis, B., \& Miraglia, M. (2008). Ochratoxin A contamination in Italian wine samples and evaluation of the exposure in the Italian population. Journal of Agricultural and Food Chemistry, 56(22), 10611.

Burdaspal, P. A., \& Legarda, T. M. (1999). Ocratoxina A en vinos, mostos y zumos de uva elaborados en España y en otros paises europeos. Alimentaria, 36 (29), 107-113. 
Dietrich, D. R., O'Brien, E., Stack, M. E., \& Heussner, A. H. (2001). Species- and sexspecific renal cytotoxicity of Ochratoxin $\mathrm{A}$ and $\mathrm{B}$ in vitro. Experimental and Toxicologic Pathology, 53 (2-3), 215-225.

Domijan, A. M., \& Peraica, M. (2005). Ochratoxin A in wine. Arhiv za Higijenu Rada i Toksikologiju, 56 (1), 17-20.

EC (2006). Commission Regulation (EC) 1881/2006 of 19 December 2006 setting maximum levels for certain contaminants in foodstuffs. Official Journal of the European Union, L364, 5-24.

EFSA (2006). Opinion of the Scientific Panel on contaminants in the food chain on a request from the commission related to ochratoxin A in food. Question N ${ }^{\circ}$ EFSA-Q2005-154. The EFSA Journal, 365, 1-56.

Flajs, D., Domijan, A. M., Ivic, D., Cvjetkovic, B., \& Peraica, M. (2009). ELISA and HPLC analysis of ochratoxin A in red wines of Croatia. Food Control, 20 (6), 590-592.

García-Granero, M. UnStat 1.0 (2010). Department of Genetics, Faculty of Sciences. University of Navarra (Spain).

Han, Z., Zheng, Y. L., Luan, L. J., Ren, Y. P., \& Wu, Y. J. (2010). Analysis of ochratoxin A and ochratoxin B in traditional Chinese medicines by ultra-highperformance liquid chromatography-tandem mass spectrometry using $\left[{ }^{13} \mathrm{C}_{20}\right]$-ochratoxin A as an internal standard. Journal of Chromatography A, 1217 (26), 4365-4374.

JECFA, Joint FAO/WHO Expert Committee on Food Additives. (2007). Evaluation of certain food additives and contaminants: Sixty-eight report of the joint FAO/WHO expert committee on food additives. WHO Technical Report Series; 947. 
López de Cerain, A., González-Peñas, E., Jiménez, A. M., \& Bello, J. (2002). Contribution to the study of ochratoxin A in Spanish wines. Food Additives and Contaminants, 19 (1), 1058-1064.

Mally, A., Keim-Heusler, H., Amberg, A., Kurz, M., Zepnik, H., Mantle, P., Volkel, W., Hard, G. C., \& Dekant, W. (2005). Biotransformation and nephrotoxicity of ochratoxin B in rats. Toxicology and applied pharmacology, 206, 43-53.

Müller, G., Burkert, B., Rosner, H., \& Köhler, H. (2003). Effects of the mycotoxin ochratoxin A and some of its metabolites on human kidney cell lines. Toxicology in Vitro, 17, 441-448.

Ng, W., Mankotia, M., Pantazopoulos, P., Neil, R. J., \& Scott, P. M. (2004). Ochratoxin A in wine and grape juice sold in Canada. Food Additives and Contaminants, 21 (10), 971-981.

O'Brien, E., Prietz, A., \& Dietrich, D. R. (2005). Investigation of the teratogenic potential of ochratoxin A and B using the FETAX system. Birth defects research. Part B, Developmental and reproductive toxicology, 74 (5), 417-423.

Otteneder, H., \& Majerus, P. (2000). Occurrence of ochratoxin A (OTA) in wines: Influence of the type of wine and its geographical origin. Food Additives and Contaminants, 17, 793-798.

Perrone, G., Nicoletti, I., Pascale, M., De Rossi, A., De Girolamo, A., \& Visconti, A. (2007). Positive correlation between high levels of ochratoxin A and resveratrol-related compounds in red wines. Journal of Agricultural and Food Chemistry, 55 (16), 68076812. 
Pfohl-Leszkowicz, A., \& Manderville, R. A. (2007). Ochratoxin A: An overview on toxicity and carcinogenicity in animals and humans. Molecular Nutrition \& Food Research, 51 (1), 61-99.

Pietri, A., Bertuzzi, T., Pallaroni, L., \& Piva, G. (2001). Occurrence of ochratoxin A in Italian wines. Food Additives and Contaminants, 18, 647-654.

Pfohl-Leszkowicz, A., \& Manderville, R. A. (2007). Ochratoxin A: An overview on toxicity and carcinogenicity in animals and humans. Molecular nutrition \& food research, 51 (1), 61-99.Quintela, S., Villarán, M. C., López de Armentia, I., \& Elejalde, E. (2011). Occurrence of ochratoxin A in Rioja Alavesa wines. Food Chemistry, 126 (1), 302-305.

Quintela, S., Villarán, M. C., López de Armentia, I., \& Elejalde, E. (2012). Ochratoxin A in Spanish exportation wine market. Food Control, 25 (2), 501-504.

Remiro, R., Ibañez-Vea, M., González-Peñas, E., \& Lizarraga, E. (2010). Validation of a liquid chromatography method for the simultaneous quantification of ochratoxin $\mathrm{A}$ and its analogues in red wines. Journal of Chromatography A, 1217 (52), 8249-8256.

Remiro, R., González-Peñas, E., Lizarraga, E., \& López de Cerain, A. (2012). Quantification of ochratoxin A and five analogs in Navarra red wines. Food Control 27 (1), 139-145.

Rosa, C. A. R., Fraga, M. E., Santana, D. M. N., Magnoli, C. E., \& Dalcero, A. M. (2004). Occurrence of ochratoxin A in wine and grape juice marketed in Rio de Janeiro, Brazil. Food Additives and Contaminants, 21, 358-364. 
Rusanova, T. Y., Beloglazova, N. V., Goryacheva, I. Y., Lobeau, M., Van Peteghem, C., \& De Saeger, S. (2009). Non-instrumental immunochemical tests for rapid ochratoxin A detection in red wine. Analytica Chimica Acta, 653 (1), 97-102.

Scheuer, R., \& Gareis, M. (2002). Occurrence of ochratoxin A and B in spices. Mycotoxin Research, 18, 62-66.

SCOOP (2002). Assessment of dietary intake of ochratoxin A by the population of EU member states. Reports on Tasks for Scientific Cooperation, task 3.2.7.

Soufleros, E. H., Bouloumpasi, E. C., \& Tricard, C. (2003). Occurrence of ochratoxin A in Greek wines. Journal of the Science of Food and Agriculture, 83, 173-179.

Spadaro, D., Lore, A., Garibaldi, A., \& Gullino, M. L. (2010). Occurrence of ochratoxin A before bottling in DOC and DOCG wines produced in Piedmont (Northern Italy). Food Control, 21 (9), 1294-1297.

Stefanaki, I., Foufa, E., Tsatsou-Dritsa, A., \& Dais, P. (2003). Ochratoxin A concentrations in Greek domestic wines and dried vine fruits. Food Additives and Contaminants, 20, 74-83.

Tabata, S., Iida, K., Kimura, K., Iwasaki, Y., Nakazato, M., Kamata, K., \& Hirokado, M. (2008). Investigation of ochratoxin A, B and citrinin contamination in various commercial foods. Journal of the Food Hygienic Society of Japan, 49 (2), 111-115.

Var, I., \& Kabak, B. (2007). Occurrence of ochratoxin A in Turkish wines. Microchemical Journal, 86 (2), 241.

Varga, J., Kiss, R., Mátrai, T., Mátrai, T., \& Téren, J. (2005). Detection of ochratoxin A in Hungarian wines and beers. Acta Alimentaria, 34 (4), 381-392. 
Visconti, A., Pascale, M., \& Centonze, G. (1999). Determination of ochratoxin A in wine by means of immunoaffinity column clean-up and high-performance liquid chromatography. Journal of Chromatography A, 864, 89-101.

Zimmerli, B., \& Dick, R. (1996). Ochratoxin A in table wine and grape-juice: Occurrence and risk assessment. Food additives and contaminants, 13, 655-668. 


\section{Tables}

Table 1: Presence of ochratoxin A in red wine samples from different countries.

\begin{tabular}{|c|c|c|c|c|c|c|}
\hline Country* & $\begin{array}{c}+^{\mathrm{a} /} \\
\mathrm{N}^{\mathrm{o}} \text { total } \\
\end{array}$ & $\%^{\mathrm{a}}$ & $\begin{array}{c}\text { Mean } \\
\left(\mu \mathrm{g} \cdot \mathrm{L}^{-1}\right)\end{array}$ & $\begin{array}{l}\text { Median }^{\mathrm{c}} \\
\left(\mu \mathrm{g} \cdot \mathrm{L}^{-1}\right)\end{array}$ & $\begin{array}{c}\text { Range } \\
\left(\mu \mathrm{g} \cdot \mathrm{L}^{-1}\right)\end{array}$ & Reference \\
\hline \multirow[t]{5}{*}{ Spain } & $66 / 72$ & 91.7 & $0.038^{\mathrm{c}}$ & NS & $<0.003-0.603^{\mathrm{c}}$ & Burdaspal and Legarda, 1999 \\
\hline & $13 / 28$ & 46.4 & $0.147^{\mathrm{a}}$ & $<0.05$ & $0.056-0.316^{\mathrm{a}}$ & López de Cerain et al., 2002 \\
\hline & $24 / 130$ & 18.5 & $0.465^{\mathrm{a}}$ & $<0.05$ & $0.06-4.24^{\mathrm{a}}$ & Bellí et al., 2004 \\
\hline & $21 / 61$ & 34.4 & $0.281^{\mathrm{b}}$ & $<0.01$ & $0.06-0.53^{\mathrm{b}}$ & Blesa et al., 2004 \\
\hline & $54 / 94$ & 57.4 & $0.037^{\mathrm{a}}$ & NS & $0.004-0.179^{\mathrm{a}}$ & Quintela et al., 2011 \\
\hline \multirow[t]{3}{*}{ France } & $8 / 8$ & 100 & $0.225^{\mathrm{ac}}$ & $\mathrm{NS}$ & $0.004-0.452^{\mathrm{ac}}$ & Burdaspal and Legarda, 1999 \\
\hline & $2 / 5$ & 40.0 & $0.028^{\mathrm{a}}$ & $<0.021$ & $0.028^{\mathrm{a}}$ & Rosa et al., 2004 \\
\hline & $13 / 14$ & 92.9 & $0.058^{\mathrm{a}}$ & NS & $0.010-0.237^{\mathrm{a}}$ & Quintela et al., 2012 \\
\hline \multirow[t]{7}{*}{ Italy } & $6 / 8$ & 75.0 & $0.052^{\mathrm{c}}$ & $\mathrm{NS}$ & $<0.003-0.191^{\mathrm{c}}$ & Burdaspal and Legarda, 1999 \\
\hline & $37 / 38$ & 97.4 & $1.24^{\mathrm{a}}$ & $0.76^{\mathrm{a}}$ & $<0.01-7.63^{\mathrm{c}}$ & Visconti et al., 1999 \\
\hline & $82^{\mathrm{b}} / 96$ & $85.4^{\mathrm{b}}$ & $0.419^{\mathrm{c}}$ & 0.090 & $<0.001-3.18^{\mathrm{c}}$ & Pietri et al., 2001 \\
\hline & $36 / 43$ & 83.7 & $0.30^{\mathrm{a}}$ & NS & $0.04-1.44^{\mathrm{a}}$ & Bacaloni et al., 2005 \\
\hline & $88^{\mathrm{b}} / 112$ & $78.6^{\mathrm{b}}$ & $0.64^{\mathrm{NS}}$ & NS & $<0.01-4.93^{\mathrm{c}}$ & Perrone et al., 2007 \\
\hline & $535 / 773$ & 69.2 & $0.34^{\mathrm{c}}$ & 0.10 & $<0.01-7.50^{\mathrm{c}}$ & Brera et al., 2008 \\
\hline & $695^{\mathrm{b}} / 1002$ & $69.4^{\mathrm{b}}$ & $0.121^{\mathrm{b}}$ & NS & $<0.0072-2.63^{\mathrm{c}}$ & Spadaro et al., 2010 \\
\hline \multirow[t]{2}{*}{ Croatia } & $7 / 7$ & 100 & $0.022^{\mathrm{ac}}$ & $0.022^{\mathrm{ac}}$ & $0.012-0.047^{\mathrm{ac}}$ & Domijan and Peraica, 2005 \\
\hline & $8 / 10$ & 80.0 & $0.015^{\mathrm{a}}$ & 0.015 & $<0.005-0.021^{\mathrm{c}}$ & Flajs et al., 2009 \\
\hline \multirow[t]{2}{*}{ Greece } & $71 / 104$ & 68.3 & $0.34^{\mathrm{c}}$ & 0.09 & $<0.05-2.69^{\mathrm{c}}$ & Stefanaki et al., 2003 \\
\hline & $9 / 14$ & 64.3 & $0.68^{\mathrm{a}}$ & 0.09 & $<0.02-2.51^{\mathrm{c}}$ & Soufleros et al., 2003 \\
\hline \multirow[t]{3}{*}{ Turkey } & $35 / 35$ & 100 & $0.728^{\mathrm{bc}}$ & $0.09^{\mathrm{bc}}$ & $0.04-1.92^{\mathrm{bc}}$ & Anli et al., 2005 \\
\hline & $44 / 51$ & 86.3 & $0.110^{\mathrm{b}}$ & NS & $<0.010-0.815^{\mathrm{c}}$ & Var et al., 2007 \\
\hline & $20 / 20$ & 100 & $2.85^{\mathrm{bc}}$ & $2.73^{\mathrm{bc}}$ & $0.39-7.96^{\mathrm{bc}}$ & Altiokka et al., 2009 \\
\hline Hungary & $33 / 33$ & 100 & $0.117^{\mathrm{ac}}$ & NS & $0.03-0.533^{\mathrm{ac}}$ & Varga et al., 2005 \\
\hline Slovakia & $12 / 18$ & 66.7 & NS & 0.011 & $<0.011-0.463^{\mathrm{c}}$ & Belajová and Rauova, 2007 \\
\hline Russia & $3 / 7$ & $42.9^{\mathrm{b}}$ & $2.9^{\mathrm{b}^{-}}$ & $<0.5$ & $1.8-4.4^{\mathrm{b}}$ & Rusanova et al., 2009 \\
\hline South America & $7 / 22$ & 31.2 & $0.039^{\mathrm{a}}$ & $<0.021$ & $0.028-0.071^{\mathrm{a}}$ & Rosa et al., 2004 \\
\hline Canada & $5 / 36$ & 13.9 & $0.024^{\mathrm{c}}$ & $<0.008$ & $<0.008-0.393^{\mathrm{c}}$ & $\mathrm{Ng}$ et al., 2004 \\
\hline
\end{tabular}


Table 2: Wine samples characteristics: origin, alcoholic percentage and interval of vintage years.

\begin{tabular}{ccc}
\hline Origin & Vintage years & \% Alcohol \\
\hline Spain & $2006-2009$ & $12.5-15$ \\
France & $2006-2009$ & $12-14.5$ \\
Italy & $2005-2008$ & $11.5-14$ \\
Croatia & $2004-2008$ & $11.5-13.5$ \\
Greece & $2003-2007$ & $11.5-13.5$ \\
Turkey & $2003-2007$ & $11.5-14.5$ \\
Israel & $2006-2009$ & $13-14.5$ \\
North-Africa & $1998-2008$ & $12-13.5$ \\
\hline
\end{tabular}


Table 3. Ochratoxin levels found in Mediterranean red wines

\begin{tabular}{|c|c|c|c|c|c|c|c|c|}
\hline \multicolumn{9}{|c|}{ Concentration $\left(\mathrm{ng} \cdot \mathrm{L}^{-1}\right)$} \\
\hline & Spain & France & Italy & Croatia & Greece & Turkey & Israel & $\begin{array}{l}\text { North } \\
\text { Africa }\end{array}$ \\
\hline \multicolumn{9}{|c|}{ Ochratoxin A } \\
\hline \% Positives ${ }^{1}$ & 100 & 91.7 & 100 & 100 & 100 & 100 & 100 & 100 \\
\hline Minimum & 1.05 & $<$ LOD & 5.18 & $0.36^{*}$ & 4.35 & 2.91 & 3.63 & 84.4 \\
\hline Maximum & 104 & 88.3 & 286 & 61.3 & 212 & 101 & 65.4 & 455 \\
\hline Mean $^{2}$ & 37.2 & 33.6 & 53.9 & 18.8 & 59.4 & 31.1 & 18.5 & 195 \\
\hline Median & 25.1 & 3.56 & 20.0 & 7.65 & 31.7 & 20.5 & 11.7 & 171 \\
\hline \multicolumn{9}{|c|}{ Ochratoxin B } \\
\hline$\%$ Positives $^{1}$ & 100 & 100 & 100 & 100 & 100 & 100 & 100 & 100 \\
\hline Minimum & 3.78 & 2.05 & 3.12 & 2.60 & 6.28 & 2.06 & 7.17 & 36.6 \\
\hline Maximum & 48.5 & 39.1 & 119 & 27.0 & 69.8 & 50.3 & 43.8 & 92.7 \\
\hline Mean $^{2}$ & 18.0 & 13.4 & 22.5 & 9.82 & 28.5 & 13.3 & 19.0 & 63.9 \\
\hline Median & 12.4 & 8.53 & 10.1 & 4.95 & 21.8 & 8.71 & 16.8 & 65.1 \\
\hline \multicolumn{9}{|c|}{ Methylochratoxin A } \\
\hline$\%$ Positives $^{1}$ & 75.0 & 58.3 & 75.0 & 16.7 & 83.3 & 41.7 & 100 & 50.0 \\
\hline Minimum & $<$ LOD & $<\mathrm{LOD}$ & $<\mathrm{LOD}$ & $<\mathrm{LOD}$ & $<\mathrm{LOD}$ & $<\mathrm{LOD}$ & 0.56 & $<$ LOD \\
\hline Maximum & 2.14 & 2.37 & 48.2 & 0.59 & 1.33 & 1.03 & 3.64 & 0.71 \\
\hline Mean $^{2}$ & 1.08 & 1.22 & 31.4 & 0.59 & 0.78 & 0.74 & 1.82 & 0.66 \\
\hline Median & 0.63 & $0.38 *$ & $0.40 *$ & $<$ LOD & $0.48 *$ & $<$ LOD & 1.73 & $0.28 *$ \\
\hline \multicolumn{9}{|c|}{ Ochratoxin C } \\
\hline$\%$ Positives $^{1}$ & 91.7 & 66.7 & 100 & 58.3 & 100 & 100 & 100 & 100 \\
\hline Minimum & $<\mathrm{LOD}$ & $<\mathrm{LOD}$ & 0.91 & $<\mathrm{LOD}$ & 0.53 & $0.27 *$ & $0.40^{*}$ & 5.92 \\
\hline Maximum & 14.3 & 7.33 & 23.5 & 3.01 & 23.5 & 11.2 & 4.41 & 31.5 \\
\hline Mean $^{2}$ & 3.93 & 3.12 & 5.09 & 1.71 & 6.04 & 3.63 & 1.91 & 14.2 \\
\hline Median & 1.80 & 0.97 & 3.26 & 0.74 & 2.92 & 1.66 & 1.20 & 12.5 \\
\hline \multicolumn{9}{|c|}{ Methylochratoxin B } \\
\hline$\%$ Positives $^{1}$ & 100 & 58.3 & 100 & 66.7 & 100 & 100 & 100 & 41.7 \\
\hline Minimum & $0.34 *$ & $<$ LOD & 1.04 & $<$ LOD & $0.29 *$ & $0.48 *$ & $0.40^{*}$ & $<$ LOD \\
\hline Maximum & 3.34 & 1.91 & 4.25 & 3.32 & 3.64 & 4.30 & 8.11 & 4.56 \\
\hline Mean $^{2}$ & 1.45 & 0.90 & 2.07 & 1.62 & 1.43 & 1.38 & 3.38 & 2.60 \\
\hline Median & 0.98 & $0.41 *$ & 1.77 & $0.30 *$ & 1.06 & 1.02 & 2.93 & $<\mathrm{LOD}$ \\
\hline \multicolumn{9}{|c|}{ Ethylochratoxin B } \\
\hline$\%$ Positives $^{1}$ & 91.7 & 50.0 & 66.7 & 91.7 & 100 & 100 & 66.7 & 100 \\
\hline Minimum & $<$ LOD & $<$ LOD & $<$ LOD & $<\mathrm{LOD}$ & $0.21 *$ & $0.19 *$ & $<$ LOD & 1.16 \\
\hline Maximum & 2.49 & 1.31 & 4.20 & 2.33 & 1.81 & 3.04 & 2.65 & 3.08 \\
\hline Mean $^{2}$ & 1.12 & 0.89 & 1.43 & 1.04 & 0.89 & 1.52 & 1.41 & 1.94 \\
\hline Median & $0.49 *$ & $0.19 *$ & $0.26^{*}$ & 0.59 & 0.56 & 0.94 & $0.39 *$ & 1.77 \\
\hline
\end{tabular}

1: > LOD; 2: > LOQ; *: LOD - LOQ. 
Table 4: Summary of ochratoxins concentrations $\left(n g \cdot \mathrm{L}^{-1}\right.$ ) found in wines of Mediterranean countries

\begin{tabular}{ccccccc}
\hline & OTB & OTA & MeOTA & OTC & MeOTB & EtOTB \\
\hline +/Total $^{\mathbf{1}}$ & $96 / 96$ & $95 / 96$ & $60 / 96$ & $86 / 96$ & $80 / 96$ & $80 / 96$ \\
\% $^{\mathbf{1}}$ & 100 & 99.0 & 62.5 & 89.6 & 83.3 & 83.3 \\
Minimum & 2.05 & $<\mathrm{LOD}$ & $<\mathrm{LOD}$ & $<\mathrm{LOD}$ & $<\mathrm{LOD}$ & $<\mathrm{LOD}$ \\
Maximum $^{2}$ & 119 & 455 & 48.2 & 31.5 & 8.11 & 4.20 \\
Mean $^{\mathbf{2}}$ & 23.5 & 54.2 & 4.22 & 5.20 & 1.85 & 1.37 \\
Median & 13.4 & 19.1 & $0.38^{*}$ & 2.32 & 0.99 & 0.62 \\
\hline
\end{tabular}

1: > LOD; 2: > LOQ; *: LOD - LOQ. 


\section{Figure captions}

Figure 1: Molecular structure of the six ochratoxins.

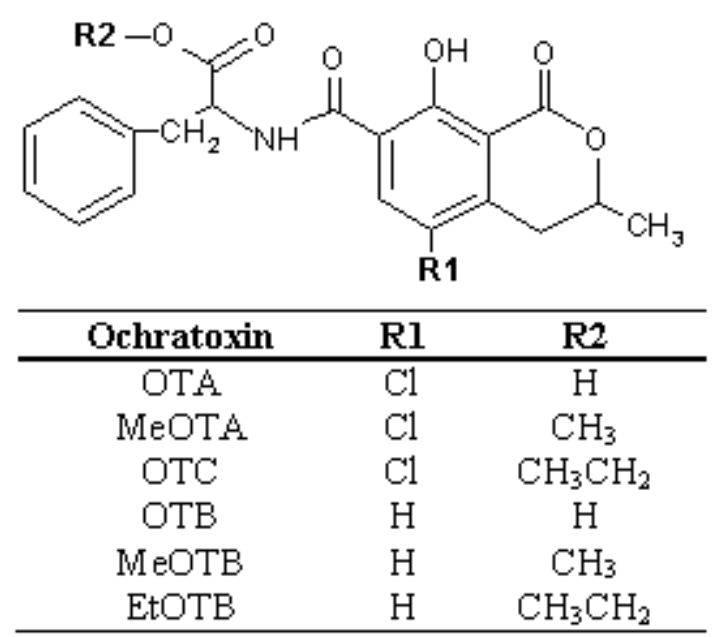


Figure 2: Spearman correlation between a) OTA-OTB concentrations and b) OTAOTC concentrations of the 96 red wine samples.
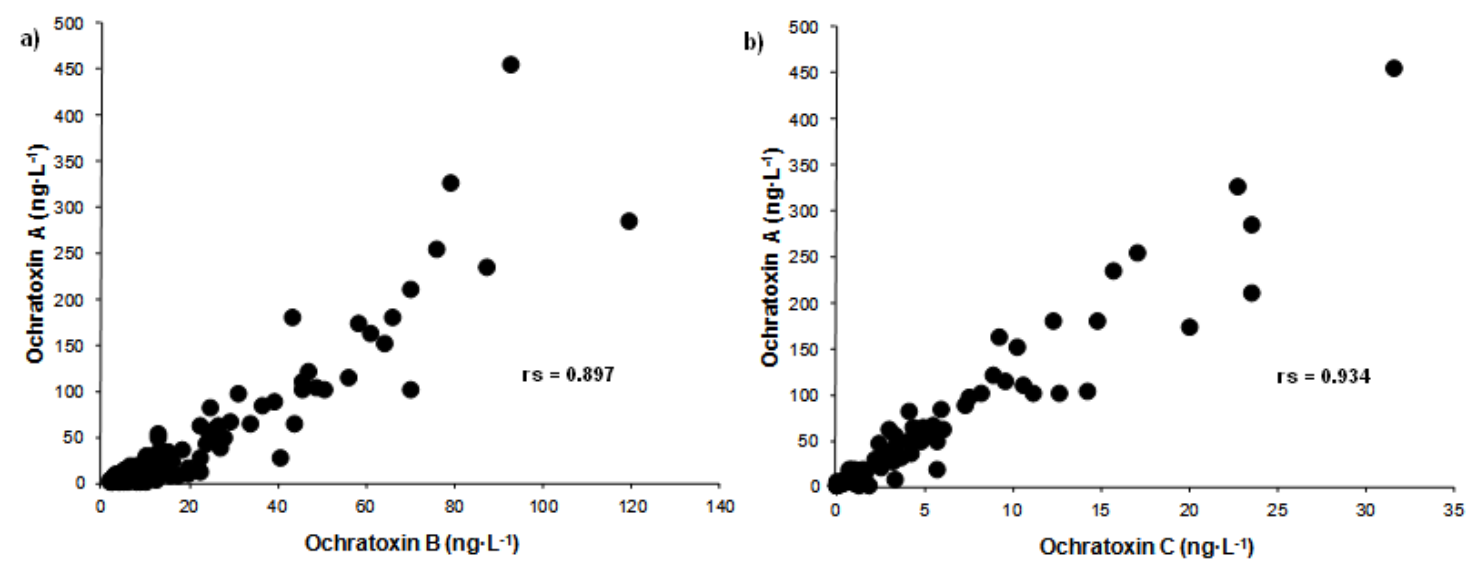